\title{
SUSTENTABILIDADE NAS FLORESTAS NATIVAS E O ENSINO DE GEOGRAFIA
}

\author{
Lourival Alves de Araújo ${ }^{1}$
}

\section{RESUMO}

A educação ambiental pode ser considera uma ação educativa que contribui para formar cidadãos mais críticos e conscientes sobre as questões socioambientais, tendo como objetivo principal colaborar para a conservação da biodiversidade, para a autorrealização individual e a comunitária e para a autogestão política e econômica, através de processos educativos que promovam a melhoria do meio ambiente e da qualidade de vida (SORRENTINO, 1995). No mesmo ideário, a Geografia possui diversos elementos essenciais capazes de ofertar subsídios e estratégia para explicar detalhes que contribuem para fortalecer o ensino. Unindo esses dois universos, construiu-se o presente artigo que possui como meta relacionar a sustentabilidade nas florestas nativas ao ensino de Geografia, dando ênfase à preservação ambiental. Dessa forma, esse estudo bibliográfico contou com referenciais teóricos como Cortez e Ortigoza (2007), Nagagata (2006), Guisso e Baiôco (2017) e Souza (2012). Foram utilizadas, da mesma forma, artigos constantes em diversos indexadores, SciELO e Scholar, e na base de dados da CAPES a fim de verificar a relevância da presente investigação. Espera-se, portanto, com essa pesquisa, destacar, nos contextos escolares de Educação Básica, a importância de se trabalhar com as florestas nativas nas aulas de Geografia, ressaltando o papel imprescindível da sustentabilidade ambiental.

Palavras-chave: Geografia; Sustentabilidade; Florestas Nativas.

\begin{abstract}
Environmental education can be considered an educational action that contributes to train more critical and conscious citizens on social and environmental issues, with the main objective of contributing to biodiversity conservation, individual and community self-realization and political and economic self-management, through educational processes that promote the improvement of the environment and quality of life (SORRENTINO, 1995). In the same way, Geography has several essential elements capable of offering subsidies and strategy to explain details that contribute to strengthen teaching. Uniting these two universes, the present article was constructed, which aims to relate sustainability in native forests to Geography teaching, emphasizing environmental preservation. Thus, this bibliographic study had theoretical references such as Cortez and Ortigoza (2007), Nagagata (2006), Guisso and Baiôco (2017) and Souza (2012). Similarly, articles contained in several indexers, SciELO and Scholar, and in the CAPES database were used in order to verify the relevance of this investigation. Therefore, it is expected, with this research, to highlight, in the school contexts of Basic Education, the importance of working with native forests in Geography classes, emphasizing the indispensable role of environmental sustainability.
\end{abstract}

Keywords: Geography; Sustainability; Native Forests.

1 Possui graduação em Ciências Contábeis pela Fundação Universidade do Tocantins (2008). Pós-graduação em: Recursos Humanos, Comunicação Empresarial, Marketing, Ciências da Educação. Mestrando em Educação pela Universidad Interamericana. E-mail: lourival.aa@hotmail.com 


\section{RESUMEN}

La educación ambiental puede considerarse una acción educativa que contribuya a formar a ciudadanos más críticos y conscientes en temas sociales y medioambientales, con el objetivo principal de contribuir a la conservación de la biodiversidad, la autorrealización individual y comunitaria y la autogestión política y económica, a través de procesos educativos que promuevan la mejora del medio ambiente y la calidad de vida (SORRENTINO, 1995). Del mismo modo, Geografía cuenta con varios elementos esenciales capaces de ofrecer subsidios y estrategia para explicar detalles que contribuyan a fortalecer la enseñanza. Uniendo estos dos universos, se construyó el presente artículo, que tiene como objetivo relacionar la sostenibilidad en los bosques nativos con la enseñanza de la Geografía, haciendo hincapié en la preservación del medio ambiente. Así, este estudio bibliográfico tuvo referencias teóricas como Cortez y Ortigoza (2007), Nagagata (2006), Guisso y Baiôco (2017) y Souza (2012). Del mismo modo, se utilizaron artículos contenidos en varios indexadores, SciELO y Scholar, y en la base de datos CAPES con el fin de verificar la relevancia de esta investigación. Por ello, se espera, con esta investigación, destacar, en los contextos escolares de Educación Básica, la importancia de trabajar con los bosques autóctonos en las clases de Geografía, destacando el papel indispensable de la sostenibilidad ambiental.

Palabras clave: Geografía; Sostenibilidad; Bosques Nativos.

\section{INTRODUÇÃO}

Como a preservação das matas e o desenvolvimento sustentável são atitudes que envolvem a formação de cidadãos conscientes, não se pode eximir a escola da responsabilidade de educar para a manutenção e consequente preservação do meio ambiente. Por esse motivo, as temáticas Educação Ambiental, sustentabilidade e floresta nativa devem ser trabalhadas por professores das diversas áreas do conhecimento a fim de mudar esse quadro.

Cortez e Ortigoza (2007) afirmam que o planeta vem sofrendo com o grande consumo da população na atualidade. Oliveira e Ramalho (2019, p. 10695) entendem que:

[...] a poluição ambiental (da terra, da água e do ar) chegou a níveis consideráveis, tão consideráveis que em determinadas regiões de alguns países o nível de poluição provoca deformidades e problemas de saúde nos habitantes locais e grande parte dos animais e vegetais já desapareceram (OLIVEIRA; RAMALHO, 2019, p. 10695).

Daí a necessidade de se refletir e buscar práticas educativas, no ambiente escolar, com o objetivo de desenvolver uma consciência ecológica na mentalidade das pessoas em todas as gerações. 
Somado a isso, cabe ainda destacar a importância de se trabalhar a educação ambiental sob a perspectiva sustentável, especialmente, em florestas nativas. Assim sendo, cabe trazer aqui as definições de "floresta" e de "florestas nativas".

Segundo a Organização das Nações Unidas para a Agricultura e Alimentação (FAO), a definição de floresta é a seguinte:

\begin{abstract}
Área medindo mais de 0,5 ha com árvores maiores que $5 \mathrm{~m}$ de altura e cobertura de copa superior a $10 \%$, ou árvores capazes de alcançar esses parâmetros in situ. Isso não inclui terra que está predominantemente sob uso agrícola ou urbano (ORGANIZAÇÃO DAS NAÇÕES UNIDAS, 1999).
\end{abstract}

Além disso, as florestas podem conter espécies classificadas em nativas, exóticas ou invasoras (IBF, 2020). Veja a divisão encontrada no site do Instituto Brasileiro de Florestas:

Espécie Nativa: planta que é natural, originária da região em que vive, ou seja, que cresce dentro dos seus limites naturais incluindo a sua área potencial de dispersão.

Espécie Exótica ou Introduzida: árvore que se estabelece para além da sua área de distribuição natural, que nasce em outro local por ter sido transportada e introduzida intencional ou acidentalmente pelo homem.

Espécie Exótica Invasora: é aquela espécie exótica que, sem a intervenção direta do homem, avança sobre outros territórios e ameaça habitats naturais ou seminaturais, causando impactos ambientais, econômicos, sociais ou culturais (IBF, 2020).

No entanto, nesta pesquisa, o foco recai sobre as florestas com espécies nativas, que, por sua vez, cumprem um papel significativo na conservação da biodiversidade e, consequentemente, ao meio ambiente.

Segundo o site "Tecnologia e Floresta" (2020), as florestas nativas precisam de um manejo adequado, isto é, de "corte seletivo de algumas árvores de modo que a floresta se recupere com o tempo" e de plantio das florestas. Assim como nas outras espécies, é preciso que, nas florestas nativas, "sejam efetuados procedimentos corretos, sustentáveis, de acordo com as leis e acompanhados por um profissional qualificado." (TECNOLOGIA E FLORESTA, 2020).

Daí a importância da educação ambiental para ensinar e incentivar a sociedade a cuidar da biodiversidade do planeta, evitando, inclusive, a extinção. 
Ainda, nota-se que há componentes que podem contribuir mais efetivamente para a formação da próxima geração no que tange à preservação das florestas como um todo. O componente curricular geografia, por exemplo, possui uma habilidade oriunda da BNCC denominada Caracterizar dinâmicas dos componentes físico-naturais no território nacional, bem como sua distribuição e biodiversidade (Florestas Tropicais, Cerrados, Caatingas, Campos Sulinos e Matas de Araucária). Dessa forma, percebe-se que compreender e conhecer bem esses ambientes poderia ser o diferencial para que haja uma maior conscientização para a não degradação desses espaços.

Desse modo, o presente estudo tem a meta principal de relacionar a sustentabilidade nas florestas nativas ao ensino de Geografia, dando ênfase à preservação ambiental.

\section{O PAPEL DO DOCENTE dE GEOGRAFIA PARA A PRESERVAÇÃo DE FLORESTAS NATIVAS}

Nos dias atuais, cada vez mais, se faz necessário discutir o tema Educação Ambiental e Sustentabilidade em florestas nas escolas, visando à conscientização de toda a comunidade escolar acerca da preservação do meio ambiente. De acordo com o trabalho de Nagagata (2006):

[...] o meio ambiente passa por um estado de depreciação nunca visto anteriormente. A cada ano, devido à exploração dos recursos naturais pelo homem, espécies de animais e plantas sofrem a ameaça de extinção. Muitas dessas espécies, desconhecidas até mesmo no meio científico, podem vir a desaparecer sem que tenhamos sequer a oportunidade de conhecê-las (NAGAGATA, 2006).

Defende-se, assim, a elaboração, nas escolas, de projetos pedagógicos que suscitem a consciência, a sensibilização e a ação dos alunos, bem como da população, acerca da sustentabilidade, a fim de proteger o meio ambiente, realizando, dentre outras práticas, a reposição florestal.

Segundo Oliveira e Ramalho (2019, p. 10695), "a produção de resíduos, a poluição do ar e a perda de biodiversidade (resultante da introdução de espécies invasoras e da extinção de espécies) são algumas das questões relacionadas com a proteção ambiental.". 


\section{A RELAÇÃO DO PROFESSOR COM A EDUCAÇÃO AMBIENTAL}

A Educação Ambiental vai além da transmissão de conhecimentos e de informações sobre os recursos naturais e as formas de preservação e conservação. É, por sua vez, um processo contínuo e longo de aprendizagem que envolve a escola, a família e a sociedade (BRANDÃO, 2004 apud LIMA, 2012, p. 1718).

No que tange à escola, faz-se necessária a participação dos professores na transformação de determinadas práticas sociais e na formação da cidadania. Segundo Paulo Freire (1981), ninguém educa ninguém. Ninguém se educa a si mesmo. Os seres humanos se educam mediatizados pelo mundo". Nessa perspectiva, o professor deixa de ser a figura central responsável pela transmissão de conhecimentos e passa a ser um facilitador da aprendizagem.

$\mathrm{Na}$ perspectiva da Educação Ambiental, o professor tem o papel de buscar, em conjunto com outros profissionais, "subsídios para que a Educação Ambiental na instituição seja uma prática diária e constante e se torna um hábito a ser incorporado à vida cotidiana." (FERREIRA; MARTINS; PEREIRA; RAGGI; SILVA, 2019, p. 203).

Assim sendo, o docente não é o ator principal, detentor de todos os saberes, mas um mediador que auxilia na descoberta de "novas práticas pedagógicas visando despertar a consciência da necessidade de conservar 0 ambiente em que vivemos, estimulando também a sustentabilidade." (FERREIRA; MARTINS; PEREIRA; RAGGI; SILVA, 2019, p. 203).

Segundo Guisso e Baiôco (2017, p. 1):

[...] o docente precisa estar aberto às mudanças compreendendo que a educação no mundo contemporâneo não pode permanecer no interior da escola, mas ao contrário, deve envolver a comunidade, atendendo às suas necessidades, assumindo a responsabilidade como cidadãos críticos, participativos e inseridos no contexto social (GUISSO; BAIÔCO, 2017, p. 1).

As autoras apontam que o professor deve também, por meio de valores e atitudes, exercer: 
[...] seu papel de cidadão em uma sociedade com inúmeros problemas socioambientais; desmatamento, poluição atmosférica, destruição da camada de ozônio, urbanização, industrialização, aquecimento global, dentre outros que coagiram o mundo, forçando a sociedade a refletir sobre educação ambiental e desenvolvimento sustentável (GUISSO; BAIÔCO, 2017, p. 1).

Além disso, é preciso que o docente exerça a sustentabilidade. Isso significa "utilizar os recursos escassos, disponíveis de forma que não comprometa o futuro das próximas gerações.". Acreditam que essa é uma tarefa difícil e dizem que "não é simples efetivar esse conceito, mas é possível, mesmo em atividades extrativistas de alto impacto ao meio ambiente, através de parâmetros de sustentabilidade." (GUISSO; BAIÔCO, 2017, p. 2).

O professor cumpre um papel importante enquanto cidadão consciente e formador de pensamentos no que se refere à preservação dos recursos naturais, em especial das florestas nativas, uma vez que pode estimular a conservação da biodiversidade, "extrair e trabalhar os recursos com eficiência, com garantia e possibilidade de recuperação das áreas exploradas" (GUISSO; BAIÔCO, 2017, p. 2).

Para as autoras, o professor tem grande importância, pois:

[...] através dele, mudanças, práticas, estratégias e didáticas interdisciplinares são traçadas, promovendo um desenvolvimento integral e em equipe, criando métodos para o exercício prático da cidadania, sintetizando as dimensões do processo socioambiental (GUISSO; BAIÔCO, 2017, p. 1).

O professor deve manter uma relação íntima com o meio ambiente, pensando em "educar para o desenvolvimento sustentável". De acordo com Guisso e Baiôco (2017, p. 2), essa é "a única maneira de sensibilizar as pessoas a informação e participação na defesa do meio ambiente e da vida em sociedade." (GUISSO; BAIÔCO, 2017, p. 2).

No que se refere à preservação das florestas, entende-se, pela visão das autoras, que o professor tem grande responsabilidade na "degradação constante da natureza". Com a Educação Ambiental, é possível chegar a uma "transformação, potencializando o envolvimento de todos numa perspectiva interdisciplinar, inovadora e crítica, voltada para a transformação social." (GUISSO; BAIÔCO, 2017). 
Acrescentam ainda que o docente deve adotar "uma ação holística, relacionando o homem, a natureza e sua responsabilidade de ação no uso dos recursos naturais." (GUISSO; BAIÔCO, 2017). Ademais, deve levar o educando a perceber os problemas ambientais do planeta, buscando possíveis soluções para o equilíbrio do meio ambiente (FREIRE, 1987).

No entanto, a fim de que os docentes tenham conhecimento e sejam capazes de atuar de forma eficiente como educadores ambientais no contexto escolar, é preciso que haja investimentos em cursos de formação inicial ou continuada.

De acordo com Monuz (1998), urge a necessidade de formar e qualificar para a função de educador ambiental não apenas os professores de Ciências Naturais, tais como Biologia e Geografia, mas todos os docentes. Cursos de formação inicial ou continuada devem ser implementados a fim de que:

[...] favoreçam a reflexão, o diálogo entre diferentes disciplinas e a construção de práticas de sala de aula embasadas por teorias sólidas de ensino/aprendizagem. Esses cursos devem também promover o encontro entre a pesquisa realizada nas universidades e os professores inseridos nas escolas públicas de Ensino Fundamental e Médio (AUGUSTO et al., 2004).

Segundo Souza (2012, p. 110), o docente deve reconhecer o potencial transformador do seu trabalho:

Só assim, eles e todos os profissionais do saber serão capazes de interagir, tanto no mundo acadêmico, quanto no mundo social. Por isso, propõe-se o engajamento dos cursos de Licenciatura e suas discussões e projetos nas questões de preservação do meio ambiente (SOUZA, 2012, p. 110).

Segundo a autora, "não basta mudar a forma de condução das aulas, inserir ou retirar conteúdos contidos no currículo." (SOUZA, 2012, p. 110). É necessária a: 
[...] formação de uma verdadeira cultura contra-hegemônica, que de um lado, seja capaz de derrubar os valores impostos pelo Deusmercado e do outro, capaz de mostrar aos atores envolvidos em diferentes lutas a importância da união em torno de um ideal maior para a construção de um projeto alternativo de mudança social (SOUZA, 2012, p. 110).

Souza (2008), citado por Souza (2012, p. 112), aponta que:

[...] apesar de muitos atuais e futuros professores desejarem trabalhar com as questões ambientais, a inserção desses temas nem sempre está associada à intenção ou à competência docente, dependendo de outros fatores, como o Projeto Político Pedagógico (PPP) da escola, direção, coordenação, tempo, falta de recursos, parcerias, entre outros. Por isso é importante que os atuais alunos das Licenciaturas e Pedagogia comecem suas vidas de professores imbuídos do desejo de transformação, sem perder a motivação com as adversidades que surgirão pelos seus caminhos (SOUZA, 2008 apud SOUZA, 2012, p. 112).

Ao tratar da Educação Ambiental, Souza (2012, p. 112) coloca que deve fazer parte da formação acadêmica do professor "analisar se pretendem ser meros transmissores de conhecimentos e compactuar com esse sistema em que o individualismo, o preconceito e as discriminações prevalecem ou se querem ter um importante papel na transformação da sociedade." (SOUZA, 2012, p. 112).

Para isso:

[...] os educadores precisarão lutar por mudanças na estrutura curricular baseada em uma grade rígida, buscar alternativas metodológicas, trabalhos interdisciplinares e uma educação consciente que não só transmita conhecimentos técnicos, mas sim, que leve aos alunos conhecimento do mundo, da realidade, que os façam pensar e os tornem pessoas críticas, que questionem o status quo (SOUZA, 2012, p. 112).

Cabe, portanto, aos professores e educadores ambientais reconhecerem seu papel de cidadão e de formador de opinião a fim de que se comprometam com uma formação mais consciente e humana de seus alunos. Assim, a sociedade, nos próximos anos, se tornará mais justa e preocupada com a conservação das florestas e a preservação do planeta. 


\section{A RELAÇÃo do PROFESSOR X ALUNO E O ENSINO VOLTADO À PRESERVAÇÃO DE FLORESTAS NATIVAS}

Conforme Freire (1992), ao falar sobre Educação, "não há docência sem discência", pois quando se ensina, há sempre alguém que aprende. Dessa forma, não se pode excluir a relação entre professor e aluno no processo de ensino e aprendizagem.

O conceito de ensino, na visão de Freire (1992), vai além da transferência de conhecimento, pois este não pode ser passado ao outro. O professor é aquele que auxilia o aluno na criação de mecanismos para a própria construção do conhecimento. Nesse sentido, o educador entende o aluno como um sujeito do processo, que é aquele que forma a si mesmo.

A relação do professor $x$ aluno passa a ser vista, sob a ótica de Freire (1992), de forma coordenada e não subordinada, uma vez que, embora diferentes, "quem forma se forma e re-forma ao formar e quem é formado formase e forma ao ser formado.". Isso significa que docente e discente não são, respectivamente, sujeito e objeto do outro, mas sujeitos do mesmo processo de conhecimento.

No modelo tradicional de educação, há a ideia de que existe um sábio, detentor de muitos conhecimentos, capaz de transferir o que aprendeu ao outro que menos sabe. Esse ensino, denominado bancário, foi muito condenado por Freire, que o classificava como autoritário, acrítico e opressor, visto que desconsidera que o conhecimento faz parte de um processo constante de busca entre as partes envolvidas.

Da mesma forma, na Educação Ambiental, em especial no que se refere à preservação das florestas, deve haver um diálogo entre professor e aluno visando à conservação dos recursos naturais do planeta. Teorias e práticas devem ser discutidas incentivando a participação dos sujeitos na natureza.

Segundo Guiso e Baiôco (2017), o professor tem o papel de interagir com diferentes temas atuais, considerando as relações entre os aspectos socioeconômicos, políticos e naturais, a fim de suscitar o interesse de seu aluno na manutenção das florestas nativas de maneira sustentável.

Discorrem sobre a relação do professor $\mathrm{x}$ aluno da seguinte forma: 
A relação professor-aluno deve partir do conhecimento das condições sociais, culturais, econômicas dos alunos, suas famílias e seu contexto, sendo permeada pelo gosto permanente que exacerba a curiosidade, que traz a eficácia de estudar com definição, em que o educador ensina e estimula o aluno a investigar, a apreciar com prazer o que the é oferecido (GUISO; BAIÔCO, 2017).

O professor pode, assim, auxiliar o aluno a desenvolver habilidades que 0 leve a perceber o meio ambiente onde se encontra, reconhecendo a sua complexidade e identificando os impactos causados pela sociedade. Assim sendo, o aluno poderá buscar caminhos sustentáveis de forma contínua e cooperativa na comunidade onde vive, incentivando, inclusive, outros sujeitos a atuarem de modo participativo.

Segundo Ferreira; Martins; Pereira; Raggi; Silva (2019, p. 213),

[...] a aquisição de novos conhecimentos estimula o desenvolvimento de uma nova visão do mundo que nos cerca. A escola configura-se como espaço privilegiado para a construção de hábitos conscientes, desenvolve o senso crítico e oportuniza a elaboração de novas práticas pedagógicas. (FERREIRA; MARTINS; PEREIRA; RAGGI; SILVA, 2019, p. 213).

O professor tem, portanto, papel fundamental de despertar em seu aluno a descoberta por soluções para os impactos ao meio ambiente que o circunda e no desenvolvimento da consciência ambiental. Para Ferreira; Martins; Pereira; Raggi e Silva (2019, p. 213): "Estimular a mudança de atitude, em busca de qualidade de vida, bem como o respeito à natureza e a compreensão de que somos agentes de transformação da sociedade representa o ápice da prática pedagógica.".

Complementam ainda que a Educação Ambiental e a Sustentabilidade, quando vividas no cotidiano das escolas, podem despertar tanto nos docentes quanto nos discentes "o entusiasmo e o compromisso de cultivar hábitos mais saudáveis e atitudes eficientes diante do problema ambiental." (FERREIRA; MARTINS; PEREIRA; RAGGI; SILVA, 2019, p. 213).

Segundo Oliveira e Ramalho (2019, p. 10698), a fim de preservar as florestas nativas, que estão degradadas por conta da perda de vegetação, solo e de partes vitais do habitat; de erosão genética; de mortalidade e baixa reprodução de espécies; dentre outros fatores, é preciso fazer a reposição 
florestal. Urge, portanto, "a necessidade de uma intervenção educativa voltada para uma restauração ecológica." (OLIVEIRA; RAMALHO, 2019, p. 10698).

Os educadores ambientais devem estimular os seus alunos à restauração ecológica, que visa "alterar intencionalmente um local para estabelecer um ecossistema.". Este processo tem a finalidade de recuperar e reabilitar as florestas, o que significa "cobrir a vegetação da terra com espécies adequadas" e utilizar "uma mistura de espécies nativas e exóticas para recuperar a área, e restaurar." (JACKSON, 1996 apud OLIVEIRA; RAMALHO, 2019, p. 10699).

Oliveira e Ramalho (2019) explicam que "a única maneira de alcançar bemestar é através do controle territorial e de boas práticas, porque permite dar suporte aos sistemas de vida a longo prazo e gerar desenvolvimento local, baseado no conhecimento e valores próprios." (OLIVEIRA; RAMALHO, 2019, p. 10700).

Os autores concluem com seu trabalho que, no que tange à relação professor-aluno:

[...] os professores têm consciência sobre a reposição florestal e as necessidades de preservação do meio ambiente para o ensino nas escolas. Concluímos que os professores percebem em grande maioria que a educação ambiental trabalhada nas escolas objetiva um ensino com mais consciência a preservação ambiental e qualidade de vida, de forma a auxiliar aos alunos a preservar a natureza, mesmo sabendo que não existe uma matéria específica para se trabalhar esta temática, se fazendo assim necessária repensar as práticas educativas no âmbito escolar (OLIVEIRA; RAMALHO, 2019, p. 10700).

Ademais, é preciso encorajar os alunos a pensar cada vez mais sobre o futuro das florestas, pois o impacto causado a elas pelas ações humanas influencia a degradação das florestas naturais e, consequentemente, o bemestar e a saúde do homem nas próximas gerações (OLIVEIRA; RAMALHO, 2019, p. 10702).

\section{PRÁtICAS DOCENTES E POLÍtICAS PÚBLICAS ENVOLVENDO A PRESERVAÇÃO AMBIENTAL}

A sustentabilidade é imprescindível para a busca de soluções às ameaças globais, "o que exige profundas mudanças nos estilos de vida e pensamento, nas formas de produzir e consumir." (BARBOSA, 2008, p. 8). Assim sendo: 
[...] as contribuições da educação ambiental para uma vida democrática mais intensa na modernidade reflexiva, como também para uma gestão política mais participativa e democrática, frequentemente empoderam os mais diversos atores e coletividades, de modo a promover o que poderíamos denominar de reinvenção da cidadania, conferindo à subpolítica (política do cotidiano) (BARBOSA, 2008, p. 8).

Por conta disso, emergiu a Política Nacional de Educação Ambiental (PNEA), Lei n 9.795/99, e sua regulamentação em 2002 a fim de incluir nos níveis de ensino formal a Educação Ambiental (EA), visando à "educação para a sustentabilidade, para uma sociedade educada ambientalmente." (BARBOSA, 2008, pp. 8-9). O autor adiciona que:

[...]o MEC, por meio da Coordenação-Geral de Educação Ambiental (CGEA), e o Ministério do Meio Ambiente, por meio do Departamento de Educação Ambiental (DEA), coordenam a PNEA e o ProNEA. Entretanto, em razão da transversalidade da EA, outras instituições públicas federais (ministérios, autarquias, estatais etc.) vêm desenvolvendo ações de EA, fato que desafia o Órgão Gestor a viabilizar ações integradas para, desse modo e a partir de uma visão sistêmica, potencializar a implementação da Política (BARBOSA, 2008, p. 9).

O ProNEA passou a ser, de fato, um orientador de políticas públicas da Educação Ambiental, em 2004, integrando "processos nacionais de EA e (re)afirmando a necessidade de uma gestão democrática e compartilhada.". (BARBOSA, 2008, p. 9). Nas palavras do autor:

O documento produzido sugere que as Comissões Interinstitucionais de Educação Ambiental (CIEAs), vistas como colegiadas estaduais representativos e democráticos, juntamente com as redes sociais em EA12, sejam fortalecidas e empoderadas, pois estimulam a participação e o exercício do controle social. (BARBOSA, 2008, p. 9).

Barbosa (2008) afirma que:

O Órgão Gestor tem buscado estimular nas unidades da Federação a gestão democrática e participativa da EA, bem como uma articulação sistêmica de ações formativas, por meio do intercâmbio de saberes, esforços e experiências de grupos e instituições de formação que tenham relação com a EA. 
Uma das iniciativas mais fecundas do OG é o programa Municípios Educadores Sustentáveis (MES), coordenado pelo DEA/MMA, pois sua implementação permite promover ações integradas que potencializam a educação ambiental na gestão municipal e no território, além da divulgação de informações e desenvolvimento de um conjunto articulado de ações ligadas à questão ambiental, à difusão de práticas para a sustentabilidade, a campanhas educacionais e socioambientais, entre outras (BARBOSA, 2008, p. 9).

O intuito dos Municípios Educadores Sustentáveis (MES) é o de fornecer espaços educadores em prol da cidadania ambiental e da participação na gestão pública. "Para tanto, são construídos arranjos educativos locais que conduzam à sustentabilidade, envolvendo o capital social comunitário." (BARBOSA, 2008, pp. 9-10).

\begin{abstract}
Ao participar do programa, além da obtenção do Selo MES quando da certificação, o município se compromete a aperfeiçoar a legislação, construir participativamente a Agenda 21 Local e elaborar projetos de captação de recursos para implementar o que for decidido pelo Comitê Local e Foros Deliberativos Regionais. O MES prevê, ainda, a criação de indicadores regionais e sistemas avaliativos e de monitoramento das ações empreendidas (BARBOSA, 2008, p. 10).
\end{abstract}

Uma ação chamada Enraizamento da Educação Ambiental nas Unidades Federativas surgiu para "induzir e fortalecer políticas públicas estaduais de EA, acompanhar as CIEAs, fortalecer as redes sociais de EA e os Coletivos Jovens de Meio Ambiente." (BARBOSA, 2008, p. 10). Ademais,

[...] propicia a articulação do Departamento de Educação Ambiental do MMA e da Coordenação Geral de Educação Ambiental do MEC com as principais instâncias públicas e entidades organizadas (coletivos, colegiados, redes, movimentos sociais etc.) em torno da EA, realizando interlocuções permanentes e trabalho cooperativo do governo federal com os Estados e o Distrito Federal (BARBOSA, 2008, p. 10).

O autor explica que "a gestão compartilhada entre os sistemas de ensino e de meio ambiente vem sendo intensificada na atual gestão do governo federal, o que possibilita sinergia e articulação entre políticas da educação formal e nãoformal." (BARBOSA, 2008, p. 10).

As políticas públicas de educação ambiental no contexto escolar estão permeadas por "concepções, princípios, objetivos ou, ainda, indicações sobre o modo de realização de trabalho com educação ambiental. As escolas podem ser 
espaços de mediação das políticas públicas de educação ambiental." (ARNALDO; SANTANA, 2018, pp. 604-605).

Por ser um espaço de mediação das políticas públicas de educação ambiental, o professor tem papel fundamental no desenvolvimento de práticas que preservem o meio ambiente. O docente pode auxiliar os estudantes a tomarem conhecimento da sua função de agente transformador social.

Segundo Loureiro (2005, p. 1.475) citado por Arnaldo e Santana (2018, pp. 600-601):

[...] desde quando foram identificadas as primeiras experiências relacionadas à educação ambiental, na década de 1970, começaram a se definir dois grandes blocos 'que historicamente alcançaram maior destaque no cenário da Educação Ambiental, seja pela proximidade com as discussões políticas da área, pela tradição na educação ou pela afinidade com teorias que obtiveram maior acúmulo no debate ambientalista' (LOUREIRO, 2005, p. 1.475 apud ARNALDO; SANTANA, 2018, pp. 600-601).

Somado a isso, Gallo (2001, p. 22) explica que a Educação Ambiental deve ser realizada no ensino de modo transversal e interdisciplinar, "não sendo uma disciplina específica do currículo, mas permeando as demais disciplinas de modo a integrar-se a elas". O autor cita ainda que "quando trabalhadas no currículo, [...] complementam-se, possibilitando uma nova dimensão social do processo educativo, que transcende o aprender pelo aprender puro e simples, desprovido de sentido sociopolítico." (GALLO, 2001, p. 22).

O professor pode, assim, desenvolver trabalhos que envolvam a transversalidade e a interdisciplinaridade por meio de projetos que entendam "a educação ambiental como possibilidade de conscientização dos sujeitos sobre questões ambientais". Ademais, o docente deve, em suas práticas, "considerar os alunos como multiplicadores dos conhecimentos sobre as questões ambientais e procurar maneiras de integrar a comunidade utilizando a temática ambiental." (ARNALDO; SANTANA, 2018, p. 616).

\section{CONSIDERAÇÕES FINAIS}

Segundo Guisso e Baiôco (2017), a Educação Ambiental pode "sensibilizar as pessoas de que somos parte do meio ambiente, buscando superar a visão antropocêntrica - onde o homem é visto como centro de tudo - deixando de lado 
a importância da natureza, da qual somos parte integrante.". (GUISSO; BAIÔCO, 2017, p. 1). Dessa forma, contribui para que a sociedade tenha mais consciência do ambiente que a cerca e reflita sobre suas práticas em florestas etc.

O professor, por sua vez, pode auxiliar no processo de aprendizagem do estudante ao desenvolver em cada um "valores e costumes que promovem transformação nos aspectos naturais e sociais para a conservação do meio ambiente, necessário à qualidade de vida e à sua sustentabilidade.". Pode, ainda, ampliar "a inquietação individual e coletiva, colaborando para o desenvolvimento de uma consciência crítica frente às questões ambientais com mudanças culturais e transformação social, ética e política." (GUISSO; BAIÔCO, 2017, p. 1).

O aluno, portanto, será capaz de mudar seu comportamento ao entender que tem uma relação próxima com o meio ambiente. Ademais, será estimulado a pensar criticamente sobre as melhores formas de aproveitar os recursos da natureza preservando-a.

O uso humano impensado e despreocupado dos recursos naturais:

[...] faz com que a sociedade degrade o meio ambiente, sendo necessárias leis de proteção por parte de organizações da sociedade civil e do governo atuando de forma educacional, preventiva e efetiva, em favor da preservação ambiental, visando garantir uma sociedade sustentável (GUISSO; BAIÔCO, 2017, p. 2).

Para a conservação das florestas nativas, por exemplo, deve-se avaliar não somente as questões econômicas, mas também a sustentabilidade, que preza por fatores éticos antes da exploração. É necessário levar em consideração o equilíbrio, a biodiversidade, dentre outros pontos, a fim de que as florestas continuem oferecendo benefícios às próximas gerações.

A escola, nesse sentido, deve compreender que a Educação Ambiental é uma disciplina extremamente necessária para a transformação social, uma vez que pode fornecer conceitos e princípios relacionados à sustentabilidade. Através dela, enquanto espaço de aprendizagem, os indivíduos poderão refletir criticamente sobre a realidade, entendendo que a economia de recursos naturais e o uso consciente da natureza garantem a conservação das florestas e mantêm a vida no planeta. 
Conforme Guisso e Baiôco (2017), "é indispensável a mudança de hábitos de consumo, criando alternativas, novos parâmetros que agenciem 0 desenvolvimento sustentável, fazendo as escolhas conscientes para que a sociedade contemporânea tenha postura responsável e ética.".

A Educação Ambiental contribui, portanto, para a mudança de crenças e hábitos que, até então, não eram pensados para a geração de bem-estar e da qualidade de vida da população. Somente com a prática desenvolvida pela Educação Ambiental, o homem pode se sentir sensibilizado com os problemas ambientais e comprometido com a preservação do mesmo.

Por fim, cabe salientar que se faz necessária a participação não apenas da escola, de professores e alunos, mas de toda a comunidade. A sociedade precisa se envolver mais nos processos de tomada de decisão relacionados aos recursos ambientais e à conservação do patrimônio natural.

\section{REFERÊNCIAS BIBLIOGRÁFICAS}

ARNALDO, M. A.; SANTANA, L. C. Políticas públicas de educação ambiental e processos de mediação em escolas de Ensino Fundamental. Ciênc. Educ., Bauru, v. 24, n. 3, 2018. p. 599-619.

AUGUSTO, T. G. S. et al. Interdisciplinaridade: Concepções de professores da área Ciências da Natureza em formação em serviço. Ciência \& Educação, São Paulo, v. 10, n. 2, p. 277-289, 2004.

BARBOSA, L. C. Políticas públicas de educação ambiental numa sociedade de risco: tendências e desafios no Brasil. IV Encontro Nacional da Anppas. Brasília - DF - Brasil. 4 - 6 de junho de 2008.

CORTEZ, A. T. C.; ORTIGOZA, S.A.G. (Orgs). Consumo Sustentável: conflitos entre necessidade e desperdício. São Paulo: Unesp, 2007.

FERREIRA, L. da C.; MARTINS, L. da C. G. F.; PEREIRA, S. C. M.; RAGGI, D. G.; SILVA, J. G. F. da. Educação ambiental e sustentabilidade na prática escolar. Revbea, São Paulo, V. 14, № 2: 201-214, 2019. 
FREIRE, P. Pedagogia do Oprimido. $4^{\mathrm{a}}$ ed. Ed. Paz e Terra. Rio de Janeiro, 1981.

FREIRE, P. Pedagogia do Oprimido. 17ª ed. Rio de Janeiro: Paz e Terra, 1987.

FREIRE, P. Pedagogia da esperança - um reencontro com a Pedagogia do oprimido. Paz e Terra, 1992.

GALLO, S. Transversalidade e meio ambiente. CICLO DE PALESTRAS SOBRE MEIO AMBIENTE, 2001.

GUISSO, L. F.; BAIÔCO, V. R. M. A educação ambiental e o papel do educador na cultura da sustentabilidade. Educação ambiental em ação. Volume XV, Número 58. Dezembro-2016/Fevereiro-2017.

INSTITUTO BRASILEIRO DE FLORESTAS. Árvores nativas e exóticas. 2020. Disponível em: https://www.ibflorestas.org.br/conteudo/arvores-nativas-eexoticas Acesso em 20 de dez. de 2020.

LOUREIRO, C. F, B. Complexidade e dialética: contribuições a práxis política e emancipatória em educação ambiental. Educação \& Sociedade, Campinas, v. 26, n. 93, p. 1473-1494, 2005.

MONUZ, M. C. G., 1998. La Educación Ambiental y formación del profesorado. Revista Iberoamericana de Educación, n. 16, p. 13-22, jan/abr. 1998.

NAGAGATA, E. A importância da Educação Ambiental como ferramenta adicional a programas de conservação. In: Rocha, C. F. D.; Bergallo, H. G.; Sluys, M. V.; Alves, M. A. S. Biologia da Conservação: Essências. São Carlos: Rima. 2006.

OLIVEIRA, A. A.; RAMALHO, M. da S. Conscientização da reposição florestal e necessidades da preservação do meio ambiente em escolas do município de novo progresso - PA. IV Seminário Internacional de Representações Sociais, Subjetividade e Educação. VI Seminário Internacional sobre 
Profissionalização Docente. Brazilian Jornal of Development. vol. 5, n. 9. 2019. pp. 10693-10708.

ORGANIZAÇÃO DAS NAÇÕES UNIDAS PARA A AGRICULTURA E ALIMENTAÇÃO. Directrizes para La ordenación de lós bosques tropicales: 1. Producción de madera. 1999. 330 p. (Estudio FAO Montes).

SORRENTINO, M. De Tibilisi a Tessaloniki. A educação Ambiental no Brasil. In Jacobi, P. et al. (orgs.). Educação, meio ambiente e cidadania: reflexões e experiências. São Paulo: SMA. 1998. p. 169-173.

SOUZA, V. M. de. A educação ambiental na formação acadêmica de professores. Conhecimento \& Diversidade, Niterói, n. 8, p. 104-114 jul./dez. 2012.

TECNOLOGIA E FLORESTA. Diferenças entre Florestas Plantadas e Nativas. Disponível em:

http://www.tecnologiaefloresta.com.br/2016/06/07/diferencas-entre-florestasplantadas-e-nativas/ Acesso em 20 de dez. de 2020. 